\title{
Examining the clinical use of hemochromatosis genetic testing
}

\author{
Matthew B Lanktree MD PhD¹, Bruce B Lanktree MD, Guillaume Paré MD MSc², John S Waye PhD²,
} Bekim Sadikovic PhD², Mark A Crowther $\mathrm{MD}^{1}$

MB Lanktree, BB Lanktree, G Paré, JS Waye, B Sadikovic, MA Crowther. Examining the clinical use of hemochromatosis genetic testing. Can J Gastroenterol Hepatol 2015;29(1):41-45.

BACKGROUND: Hereditary hemochromatosis leads to an increased lifetime risk for end-organ damage due to excess iron deposition. Guidelines recommend that genetic testing be performed in patients with clinical suspicion of iron overload accompanied by elevated serum ferritin and transferrin saturation levels.

OBJECTIVE: To evaluate guideline adherence and the clinical and economic impact of HFE genetic testing.

METHODS: The electronic charts of patients submitted for HFE testing in 2012 were reviewed for genetic testing results, biochemical markers of iron overload and clinical history of phlebotomy.

RESULTS: A total of 664 samples were sent for testing, with clinical, biochemical and phlebotomy data available for 160 patients. A positive C282Y homozygote or C282Y/H63D compound heterozygote test result was observed in $18 \%$ of patients. Patients with an at-risk HFE genotype had significantly higher iron saturation, serum iron and hemoglobin $(\mathrm{P}<0.001)$, without higher ferritin or liver enzyme levels. Fifty percent of patients referred for testing did not have biochemical evidence of iron overload (transferrin saturation $>45 \%$ and ferritin level $>300 \mu \mathrm{g} / \mathrm{L}$ ). Patients were four times more likely to undergo phlebotomy if they were gene test positive (RR 4.29 [95\% CI 2.35 to 7.83]; $\mathrm{P}<0.00001$ ).

DISCUSSION: One-half of patients referred for testing did not exhibit biochemical evidence of iron overload. Many patients with biochemical evidence of iron overload, but with negative genetic test results, did not undergo phlebotomy. A requisition to determine clinical indication for testing may reduce the use of the HFE genetic test. Finally, improvement of current genetic test characteristics would improve rationale for the test.

CONCLUSION: A significant proportion of hemochromatosis genetic testing does not adhere to current guidelines and would not alter patient management.

Key Words: Genetic testing; Hemochromatosis; Iron; Phlebotomy

$\mathrm{H}$ ereditary hemochromatosis is a common genetic condition in which elevated total body iron stores leads to iron deposition in the liver, heart, pancreas, skin, joints, pituitary gland and testes, resulting in liver cirrhosis, heart failure, arthritis, diabetes, skin bronzing, endocrine abnormalities and cancer (1). In 1996, two missense mutations in the hemochromatosis gene (HFE) were identified to be a cause of hereditary hemochromatosis, leading to an increase in our understanding of iron metabolism, the pathophysiology of hemochromatosis and the genetic test that is still performed today (2).

The genetic test for hemochromatosis most commonly involves genotyping of a cysteine-to-tyrosine substitution at amino acid position 282 (C282Y) and a histidine-to-aspartic acid substitution at amino acid position 63 (H63D) in the HFE gene. A positive genetic test is defined as two copies (homozygosity) of the C282Y allele, or one C282Y allele

\section{Examen de l'utilisation clinique du test de dépistage génétique de l'hématochromatose}

HISTORIQUE : L'hématochromatose héréditaire s'associe à un plus grand risque à vie de dommage aux organes cibles causé par un dépôt excessif de fer. Les lignes directrices recommandent d'effectuer un test de dépistage génétique en cas de suspicion clinique de surcharge en fer accompagnée d'un taux élevé de ferritine sérique et d'une saturation de la transferrine.

OBJECTIF : Évaluer le respect des lignes directrices et les répercussions cliniques et économiques du test HFE.

MÉTHODOLOGIE : Les chercheurs ont examiné le dossier électronique des patients qui devaient subir un test HFE en 2012 afin de connaître leurs résultats génétiques, leurs marqueurs biochimiques de surcharge en fer et leurs antécédents cliniques de phlébotomie.

RÉSULTATS : Au total, 664 échantillons ont été envoyés au dépistage, et les chercheurs ont obtenu les données cliniques, les données biochimiques et la phlébotomie de 160 patients. Chez $18 \%$ d'entre eux, le test a décelé une homozygotie C282Y ou une hétérozygotie composite C282Y et $\mathrm{H} 63 \mathrm{D}$. Les patients présentant un génotype HFE à risque avaient une saturation en fer, en fer sérique et en hémoglobine considérablement plus élevée $(\mathrm{P}<0,001)$, sans augmentation de leur taux de ferritine ou d'enzymes hépatiques. Cinquante pour cent des patients aiguillés pour le test ne présentaient pas de manifestations biochimiques de surcharge en fer (saturation en transferrine $>45 \%$ et taux de ferritine $>300 \mu \mathrm{g} / \mathrm{L}$ ). Les patients étaient quatre fois plus susceptibles de subir une phlébotomie si le test génétique était positif (RR 4,29 [95 \% IC 2,35 à 7,83]; $\mathrm{P}<0,00001$ ). EXPOSÉ : La moitié des patients aiguillés pour subir le test ne présentaient pas de manifestations biochimiques de surcharge en fer. De nombreux patients qui présentaient des manifestations biochimiques de surcharge en fer, mais dont les résultats du test génétique étaient négatifs, n'ont pas subi de phlébotomie. Une réquisition pour établir l'indication clinique d'effectuer le test HFE peut en réduire l'utilisation. Enfin, en améliorant les caractéristiques du test génétique actuel, on en justifierait mieux l'utilisation.

CONCLUSION : Une proportion marquée de tests génétiques de l'hémochromatose ne respecte pas les lignes directrices et ne changerait pas la prise en charge des patients.

with an H63D allele on the other chromosome, termed 'compound heterozygosity'. Fewer than $0.5 \%$ of individuals of European ancestry are homozygous for C282Y, with lower prevalence in other ethnicities (3).

The penetrance of the $\mathrm{C} 282 \mathrm{Y}$ variant for iron accumulation leading to end-organ disease in one's lifetime, which also represents the positive predictive value of the genetic test, has been evaluated in prospective, retrospective and cross-sectional studies (4). Differences in study populations and disease definitions have yielded a wide range of estimates from $0 \%$ to $75 \%$ (4). Cross-sectional studies including large numbers of patients may underestimate lifetime risk because they may evaluate patients before they have developed the outcome and may rely on imperfect measures of disease diagnosis (5). Alternatively, prospective studies that follow small numbers of patients may identify disease that may not be clinically relevant (6). Moreover, penetrance

\footnotetext{
${ }^{1}$ Department of Medicine; ${ }^{2}$ Department of Pathology and Molecular Medicine, McMaster University, Hamilton, Ontario

Correspondence: Dr Matthew B Lanktree, Department of Medicine, McMaster University, 1200 Main Street West, Room 3W10A-C, Hamilton,

Ontario L8N 3Z5. E-mail matthew.lanktree@medportal.ca
}

Received for publication October 23, 2014. Accepted December 5, 2014 
is significantly different between men and premenopausal women, given the protection yielded by menses. Nevertheless, overall estimates from a meta-analysis of current clinical guidelines suggests a lifetime penetrance and, hence, positive predictive value of $13 \%$ (4).

The sensitivity of the current hemochromatosis genetic test is represented by the prevalence of individuals who test positive if they have developed end-organ iron overload damage. Estimates are again affected by the population observed and the gold standard used for diagnosis, but have ranged from $75 \%$ to $90 \%$ (4,7-9). Given that hemochromatosis exists in nonwhite populations, and the low prevalence of $\mathrm{C} 282 \mathrm{Y}$ in nonwhite ethnicities, the sensitivity of the test is reduced in these populations (10). Non-C282Y HFE polymorphisms (such as H63D) have smaller effects on iron accumulation risk and may improve the sensitivity of a genetic test, but consequently negatively affect specificity because the penetrance of H63D is quite low (11). In general, patients with a negative genetic test may still develop iron overload, while $80 \%$ to $90 \%$ of individuals with a positive genetic test may never develop iron overload (4).

Over the past decade, considerable debate has occurred with regard to the appropriate clinical context in which to order genetic testing for hemochromatosis (11-13). Current guidelines published by the European Association for the Study of the Liver (4) and American Association for the Study of Liver Diseases (7) recommend against genetic testing for hemochromatosis in the absence of clinical suspicion for hemochromatosis, with the exception of siblings of confirmed HFE C282Y homozygotes with clinical hemochromatosis (ie, genetic screening of unaffected individuals is inappropriate). Hence, genetic testing of patients should be limited to individuals with elevated transferrin saturation ( $>45 \%$ in women and $>50 \%$ in men) and serum ferritin level $(>300 \mu \mathrm{g} / \mathrm{L})$. Strategies investigating alternative causes of elevated ferritin levels and transferrin saturation followed by serial genetic investigations has also been proposed $(13,14)$.

Phlebotomy can be both diagnostic and therapeutic because it removes excess iron, and the response to phlebotomy is an indicator of the quantity of iron present (4). Individuals with pathological iron overload will require removal of many grams of iron while those with other causes of elevated ferritin levels and transferrin saturation will generally experience a rapid fall in iron levels (4). Phlebotomy should be initiated in patients with suspected iron excess and continued until ferritin level has dropped to $<50 \mu \mathrm{g} / \mathrm{L}$, although no randomized control trials have been performed to support its use (4). Phlebotomy is safe in patients with advanced liver fibrosis or cirrhosis, and may improve arthropathies, diabetes, hypogonadism and hypothyroidism (4).

The cost of genetic testing for hemochromatosis has not changed substantially in the past decade despite immense improvements in genotyping technology. The cost of DNA extraction and singlenucleotide genotyping in a high-throughput research environment has plummeted, but because overhead costs, data storage and data integrity issues have remained constant, cost estimates from $\$ 150$ to $\$ 500$ per test have persisted (15).

To better understand the use of hemochromatosis genetic testing in current practice, we sought to identify the clinical and biochemical characteristics of patients submitted to a tertiary care laboratory in Hamilton, Ontario. Finally, we examined factors that may have impacted the clinician's decision to provide phlebotomy.

\section{METHODS}

Ethics approval to retrospectively review patient records was granted by the Hamilton Integrated Research Ethics Board (approval number 13-323-C). Data were collected from the electronic patient record (EPR) of Hamilton Health Sciences and included all patients referred for genetic testing for hemochromatosis in the 2012 calendar year. Hamilton Health Sciences is an academic tertiary care medical facility serving a catchment of 2.3 million Canadians. In total, the EPR of 620 patients were manually accessed to obtain genetic test results, biochemical markers of iron overload, biochemical markers of endorgan damage resulting from iron accumulation and clinical history of phlebotomy. Specifically, data included genotype at HFE C282Y and H63D, maximum ferritin, transferrin saturation, aspartate transaminase, alanine transaminase, gamma-glutamyl transpeptidase, alkaline phosphatase, glycated hemoglobin, fasting glucose, hemoglobin concentration and minimum mean corpuscular volume. Phlebotomy status was primarily ascertained by examining the 'reason for visit' field within the appointment scheduling system of the EPR, as well as manual review of the free-text consultation and progress notes. The type of physician who had made the referral was also available. Unfortunately, patients who had not required hospitalization for any reason, nor received evaluation by a hematologist or gastroenterologist, but were referred for genetic testing by a community primary care physician would not have clinical data available in the Hamilton Health Sciences EPR.

Data are expressed as counts and percentages for categorical variables, and mean \pm SD or median (interquartile range) for continuous data depending on their distribution. Comparisons between groups were performed using $\chi^{2}$ and ANOVA tests.

\section{RESULTS}

In total, 664 patients were submitted for hemochromatosis genetic testing, including nine repeated tests; 177 (26\%) of patients were female. The observed minor allele frequency was $18 \%$ for $\mathrm{C} 282 \mathrm{Y}$ and $20 \%$ for H63D, yielding 49 (8.1\%) C282Y homozygotes and 49 (8.1\%) C282Y/ H63D compound heterozygotes, corresponding to an overall positive test rate of $16.2 \%$ (Table 1). Of 655 patients, 449 (68.5\%) did not carry a C282Y allele. There was no significant difference in the rate of positive tests ordered by family physicians verses those ordered by specialists.

Of those referred for testing, clinical and biochemical data were available for 160 patients. Transferrin saturation and ferritin level data were available for 96 patients, and evidence of iron overload (measured transferrin saturation $>45 \%$ and ferritin $>300 \mu \mathrm{g} / \mathrm{L}$ ) was present in $48(50 \%)$. Comparing biochemical characteristics between those with positive hemochromatosis genetic testing results (either C282Y/ C282Y or C282Y/H63D) had significantly higher transferrin saturation, hemoglobin and serum iron concentrations $(\mathrm{P}<0.001)$ (Table 2). There was no increase in either ferritin or liver enzyme levels in the group with a positive genetic test.

Phlebotomy was performed in 33 patients, 20 of whom were hemochromatosis gene test positive and 13 who were not. For a given ferritin level or transferrin saturation, patients were significantly more likely to undergo phlebotomy if they were gene test positive $(\mathrm{P}<0.01)$. The likelihood of undergoing phlebotomy for a given ferritin level and transferrin saturation is presented in decision-tree format in Figure 1. Examining the test characteristics of the hemochromatosis genetic test for subsequent need for phlebotomy in this clinically ascertained sample, in which genotype likely affected the decision to provide phlebotomy, the sensitivity for subsequent need for phlebotomy was $60 \%$ (95\% CI $43 \%$ to $75 \%$ ), with a specificity of $82 \%$ (95\% CI $75 \%$ to $88 \%)$ and an RR of 4.29 (95\% CI 2.35 to 7.83 [Fisher's exact $\mathrm{P}<0.00001])$. The positive predictive value was $47 \%$ (95\% CI $35 \%$ to $59 \%$ ) and the positive likelihood ratio was 3.47 (95\% CI 2.06 to 5.41 ).

\section{DISCUSSION}

The results of a retrospective analysis of 664 hemochromatosis genetic tests performed at a tertiary care academic medical centre in the 2012 calendar year indicates that a substantial proportion of hemochromatosis genetic testing was performed out of accordance with currently published guidelines. Additionally, hemochromatosis genetic testing appears to be affecting the decision to provide phlebotomy without solid evidence to support the practice. We believe that more stringent access to genetic testing for hemochromatosis may reduce the amount of unnecessary testing without adversely affecting patient care. Finally, improvements in the test characteristics of the hemochromatosis genetic test, and prospective randomized studies designed to appropriately direct its use, would lead to both cost savings and improvement in patient care. 
TABLE 1

\section{Genetic testing results}

\begin{tabular}{lccc}
\hline HFE genotype & Family physicians & Specialists* $^{*}$ & Total \\
\hline 282Y/282Y & $20(7.1)$ & $29(9.0)$ & $49(8.1)$ \\
282Y/63D & $22(7.8)$ & $27(8.4)$ & $49(8.1)$ \\
Negative & $241(85.2)$ & $265(82.6)$ & $506(83.8)$ \\
\hline
\end{tabular}

Data presented $n$ (\%). *Specialists include (in order of prevalence): gastroenterologists, hematologists and cardiologists. HFE Hemochromatosis gene

Who should undergo genetic testing for hemochromatosis?

Current guidelines suggest confirmatory genetic testing in patients with clinical suspicion and biochemical evidence of iron accumulation $(4,7)$. A diagnostic and therapeutic trial of phlebotomy may be indicated in these patients regardless of genetic testing results. Nevertheless, ferritin levels and transferrin saturations were available for only 96 patients sent for genetic testing and only one-half of these fulfilled biochemical criteria for possible iron overload. It is possible that more of the patients had ferritin and transferrin testing performed, which was unavailable for the present retrospective analysis; however, a large proportion of patients who are undergoing the genetic test do not have biochemical evidence of iron overload.

It is possible that a proportion of patients that received genetic testing without iron accumulation were first-degree relatives of homozygous $\mathrm{C} 282 \mathrm{Y}$ hemochromatosis patients, and negative genetic testing results may reduce the need for serial transferrin and ferritin measurements in the future. This remains a poor explanation because $68.5 \%$ of those tested did not carry a C282Y allele, which is unlikely if they are a first-degree relative of homozygous C282Y hemochromatosis patients. The cost for ferritin and transferrin measurements is approximately $\$ 25$ each (16). Additionally, first-degree relatives may still be at elevated risk if a non-HFE C282Y mechanism is the reason for iron accumulation.

So-called 'shotgun' investigations, in which multiple investigations are simultaneously ordered to cover a range of potential pathogenic mechanisms in patients with elevated liver enzyme levels, porphyria cutanea tarda, hepatocellular carcinoma, type 1 diabetes or well-defined chondrocalcinosis, may represent a portion of the hemochromatosis genetic testing. However, given the slow rate of disease progression of hemochromatosis, a staggered approach in which genetic testing follows measurement of ferritin levels and transferrin saturation appears to be more appropriate.

In general, our results suggest that a large proportion of current hemochromatosis genetic testing is unlikely to provide diagnostic certainty, change patient management or comply with current guidelines.
TABLE 2

Clinical characteristics according to HFE test result

\begin{tabular}{lcc}
\hline & \multicolumn{2}{c}{ HFE test result } \\
\cline { 2 - 3 } Characteristic & Positive & Negative \\
\hline $\mathrm{n}$ & 42 & 117 \\
Age, years & $54.3 \pm 13.6$ & $56.3 \pm 13.7$ \\
Female sex, $\mathrm{n}(\%)$ & $13(28)$ & $35(30)$ \\
Maximum ferritin, $\mu \mathrm{g} / \mathrm{L}$ & $864 \pm 607$ & $901 \pm 862$ \\
Maximum transferrin saturation, \% & $62 \pm 23^{*}$ & $46 \pm 20^{*}$ \\
Maximum serum iron, umol/L & $121 \pm 6.5^{\star}$ & $21.5 \pm 7.7^{\star}$ \\
Maximum hemoglobin, g/L & $155 \pm 9.4^{*}$ & $144 \pm 20^{*}$ \\
Minimum mean corpuscular volume, fL & $93.8 \pm 5.8$ & $91 \pm 11$ \\
Maximum aspartate aminotransferase, U/L & $68 \pm 20$ & $1001 \pm 36$ \\
Maximum alanine aminotransferase, U/L & $110 \pm 30$ & $156 \pm 42$ \\
Maximum gamma-glutamyl transpeptidase, U/L & $55 \pm 17$ & $208 \pm 75$ \\
Maximum alkaline phosphatase, U/L & $66 \pm 12$ & $151 \pm 41$ \\
Viral hepatitis, $\mathrm{n}$ (\%) & $2(4.7)$ & $11(9.4)$ \\
Received phlebotomy, $\mathrm{n}(\%)$ & $27(64)^{*}$ & $12(10)^{*}$ \\
\hline
\end{tabular}

Data presented as mean $\pm S D$ unless otherwise indicated. ${ }^{*} P<0.001$. HFE Hemochromatosis gene

Efforts to improve education regarding the indications for hemochromatosis genetic testing may reduce the quantity of unnecessary testing. Finally, a laboratory requisition form for hemochromatosis genetic testing, including the indication for the test and measured ferritin levels and transferrin saturation, would enable more accurate evaluation of hemochromatosis genetic testing in the future and would prevent unnecessary testing.

Should the current HFE genetic test affect the decision to phlebotomize?

Clinicians need to incorporate information from history, physical investigations and patient preferences to evaluate the pros and cons of phlebotomy in a particular patient. Factors to be considered before offering phlebotomy are included in Box 1 . The decision-tree in Figure 1 attests that the decision is not simply based on ferritin level, transferrin saturation and genotype. However, genotype does appear to affect the decision to provide phlebotomy in these data. To date, there exists a dearth of evidence that individuals with HFE C282Y-associated hemochromatosis respond differently to phlebotomy than those with non-HFE C282Y iron accumulation. Thus, while a positive test may increase the likelihood of pathogenic iron accumulation, a trial of phlebotomy is the gold standard for diagnosis.

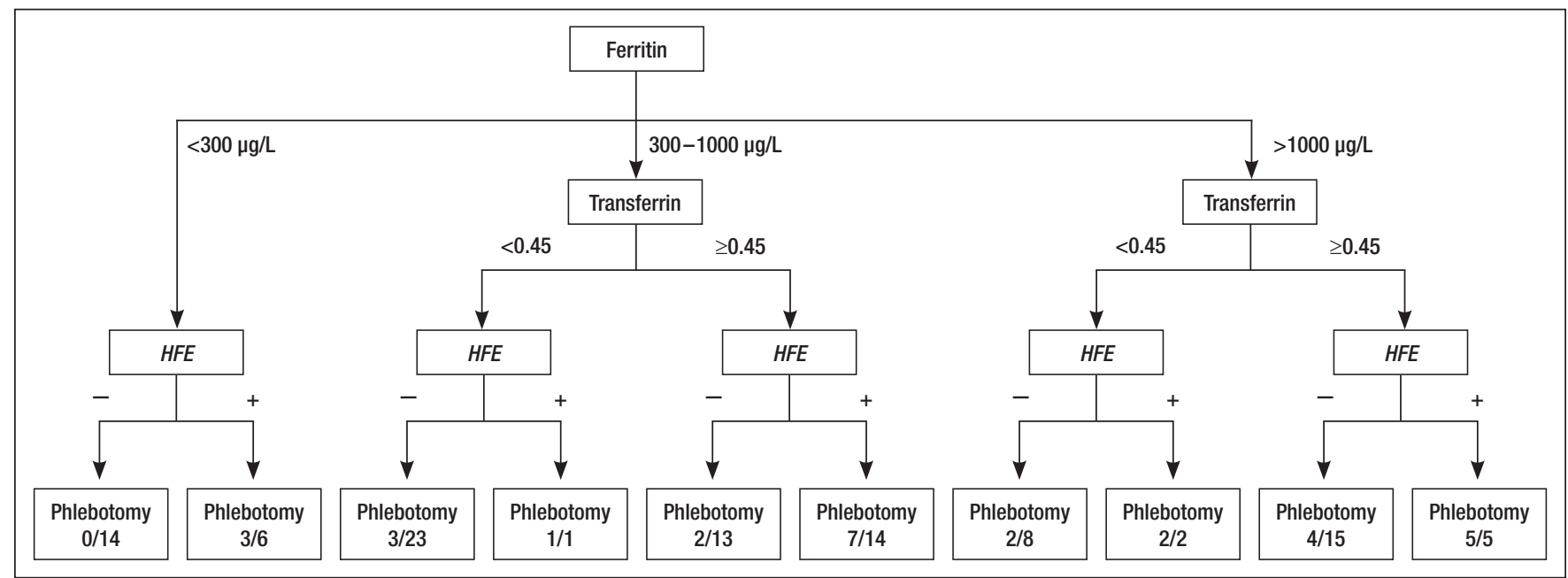

Figure 1) Decision-tree analysis. HFE Hemochromatosis gene 


\section{BOX 1}

Factors affecting to the decision to phlebotomize

- Serum iron parameters (transferrin saturation, ferritin)

- Hemoglobin

- Presence of alternative explanation

- Alcohol use/abuse

- Metabolic syndrome

- Nonalcoholic steatohepatitis

- Viral hepatitis

- Inflammatory states (infectious, autoimmune)

- Noninvasive liver imaging (ultrasound, Fibroscan [Ecosens, France], computed tomography)

- Evidence of iron overload on liver biopsy

- Hemochromatosis gene (HFE) genotype

- Comorbidities

- Patient's goals of care

- Ease of access to facilities

- Tolerability of procedure (orthostasis)

Can hemochromatosis genetic test performance be improved? Hemochromatosis is a complex disease with substantial genetic heterogeneity. While HFE C282Y is found in $80 \%$ of patients with clinical hemochromatosis (4), other genetic causes of hemochromatosis have been described. These include rare mutations and deletions in HFE undetected by standard clinical tests, and mutations in four other genes (hepcidin [HAMP], hemojuvelin [HFE2, previously HJV], transferrin receptor 2 [TFR2] and ferroportin [SLC40A1]) $(17,18)$. Mutations that affect ferritin concentration (a common marker used to identify iron overload) but do not lead to iron accumulation, have been observed in the ferritin light chain (FTL) gene (19). Adding to the complexity, common polymorphisms in 14 additional genes have been associated with variation in iron metabolism in the general population and in hemochromatosis patients (10,20-22). Environmental exposures, including diet, alcohol and medication use, can also significantly alter the risk of pathological iron accumulation. Given the complexity, it is not surprising that the genotyping of only the two single-nucleotide

\section{REFERENCES}

1. Pietrangelo A. Hereditary hemochromatosis - a new look at an old disease. N Engl J Med 2004;350:2383-97.

2. Feder JN, Gnirke A, Thomas W, et al. A novel MHC class I-like gene is mutated in patients with hereditary haemochromatosis. Nat Genet 1996;13:399-408.

3. Steinberg KK, Cogswell ME, Chang JC, et al. Prevalence of C282Y and H63D mutations in the hemochromatosis (HFE) gene in the United States. JAMA 2001;285:2216-22.

4. EASL clinical practice guidelines for HFE hemochromatosis. J Hepatol 2010;53:3-22.

5. Beutler E, Felitti VJ, Koziol JA, Ho NJ, Gelbart T. Penetrance of $845 \mathrm{G} \rightarrow \mathrm{A}(\mathrm{C} 282 \mathrm{Y})$ HFE hereditary haemochromatosis mutation in the USA. Lancet 2002;359:211-8.

6. Olynyk JK, Hagan SE, Cullen DJ, Beilby J, Whittall DE. Evolution of untreated hereditary hemochromatosis in the Busselton population: A 17-year study. Mayo Clin Proc 2004;79:309-13.

7. Bacon BR, Adams PC, Kowdley KV, Powell LW, Tavill AS. Diagnosis and management of hemochromatosis: 2011 practice guideline by the American Association for the Study of Liver Diseases. Hepatology 2011;54:328-43.

8. Pietrangelo A, Caleffi A, Corradini E. Non-HFE hepatic iron overload. Semin Liver Dis 2011;31:302-18.

9. Asberg A, Hveem K, Thorstensen K, et al. Screening for hemochromatosis: High prevalence and low morbidity in an unselected population of 65,238 persons. Scand J Gastroenterol 2001;36:1108-15.

10. McLaren CE, McLachlan S, Garner CP, et al. Associations between single nucleotide polymorphisms in iron-related genes and iron status in multiethnic populations. PLoS One 2012; 7:e38339. polymorphisms in HFE yields a test that is not particularly sensitive nor specific for iron accumulation leading to end-organ damage. Test performance in non-European ethnicities is even worse given the low background frequency of the C282Y allele (10).

Schranz et al (13), suggested a staggered approach to testing with targeted sequencing of HFE, TFR2, HFE2, (HJV), HAMP and SLC40A1 (13). Given the drastically declining cost of DNA sequencing via sequence capture and next-generation sequencing technologies, the production of a test that obtains all DNA variations in iron metabolism genes at a low cost is needed. A similar strategy has already been used for conditions such as hypertrophic cardiomyopathy and dyslipidemia $(23,24)$. Barriers to the interpretation of next-generation sequencing data exist as many variants of unknown significance. Nevertheless, commercial testing using this strategy is already available <www.invitae.com/en/physician/condition-detail/CND0033/>.

\section{Limitations of the current study}

The most significant limitation of the current study was its retrospective chart review design. Data were extracted from the records of a selected hospital-based population, biasing the study toward the presence of more severely affected patients. Patients may have been instructed to attend blood donation clinics, which would not have entered our records as having undergone a phlebotomy. While a clinical trial randomly assigning patients to phlebotomy may not be ethically feasible, a prospectively collected cohort with stringent data collection protocols may mitigate bias in the evaluation of nextgeneration genetic tests for hemochromatosis.

\section{CONCLUSIONS}

The present retrospective chart review suggests that a large percentage of hemochromatosis genetic testing was performed on patients without iron accumulation and would not alter their diagnosis, prognosis or management. Patients with evidence of iron overload were more likely to receive phlebotomy in the presence of a positive test when those with negative tests, especially nonEuropeans, may still benefit.

DISCLOSURES: The authors have no financial disclosures or conflicts of interest to declare.

11. Adams PC. H63D genotying for hemochromatosis: Helper or hindrance? Can J Gastroenterol Hepatol 2014;28:179-80.

12. Waalen J, Felitti VJ, Gelbart T, Beutler E. Screening for hemochromatosis by measuring ferritin levels: A more effective approach. Blood 2008;111:3373-6.

13. Schranz M, Talasz H, Graziadei I, et al. Diagnosis of hepatic iron overload: A family study illustrating pitfalls in diagnosing hemochromatosis. Diagn Mol Pathol 2009;18:53-60.

14. Aguilar-Martinez P, Grandchamp B, Cunat S, et al. Iron overload in HFE C282Y heterozygotes at first genetic testing: A strategy for identifying rare HFE variants. Haematologica 2011;96:507-14.

15. Chandrasekharan S, Pitlick E, Heaney C, Cook-Deegan R. Impact of gene patents and licensing practices on access to genetic testing for hereditary hemochromatosis. Genet Med 2010;12(4 Suppl):S155-70.

16. VanWagner LB, Green RM. Elevated serum ferritin. JAMA 2014;312:743-4.

17. Barton JC, Lafreniere SA, Leiendecker-Foster C, et al. HFE, SLC40A1, HAMP, HJV, TFR2, and FTL mutations detected by denaturing high-performance liquid chromatography after iron phenotyping and HFE C282Y and H63D genotyping in 785 HEIRS Study participants. Am J Hematol 2009;84:710-4.

18. Del-Castillo-Rueda A, Moreno-Carralero MI, Cuadrado-Grande N, et al. Mutations in the HFE, TFR2, and SLC40A1 genes in patients with hemochromatosis. Gene 2012;508:15-20.

19. Yin D, Kulhalli V, Walker AP. Raised serum ferritin concentration in hereditary hyperferritinemia cataract syndrome is not a marker for iron overload. Hepatology 2014;59:1204-6. 
20. Pelucchi S, Mariani R, Calza S, et al. CYBRD1 as a modifier gene that modulates iron phenotype in HFE p.C282Y homozygous patients. Haematologica 2012;97:1818-25.

21. van der Harst P, Zhang W, Mateo Leach I, et al. Seventy-five genetic loci influencing the human red blood cell. Nature 2012;492:369-75.

22. McLaren CE, Garner CP, Constantine CC, et al. Genome-wide association study identifies genetic loci associated with iron deficiency. PLoS One 2011;6:e17390.
23. Johansen CT, Dubé JB, Loyzer MN, et al. LipidSeq: A next-generation clinical resequencing panel for monogenic dyslipidemias. J Lipid Res 2014;55:765-72.

24. Millat G, Chanavat V, Rousson R. Evaluation of a new NGS method based on a custom AmpliSeq library and Ion Torrent PGM sequencing for the fast detection of genetic variations in cardiomyopathies. Clin Chim Acta 2014;433:266-71. 


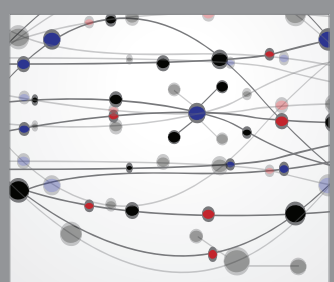

The Scientific World Journal
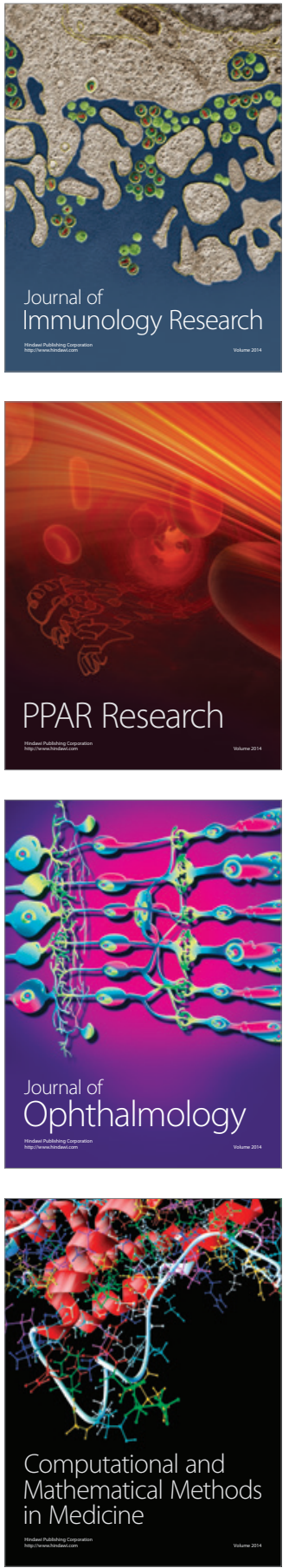

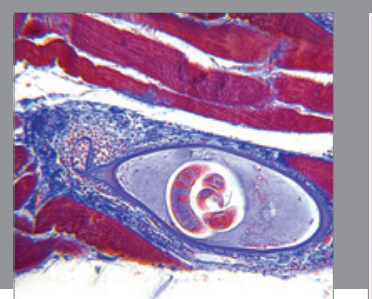

Gastroenterology Research and Practice

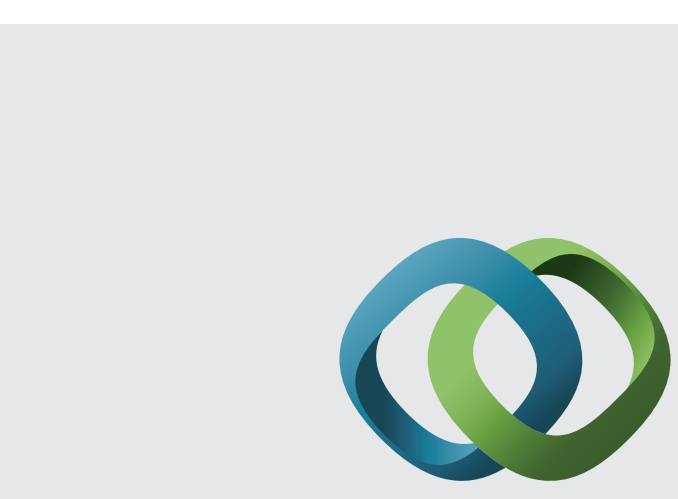

\section{Hindawi}

Submit your manuscripts at

http://www.hindawi.com
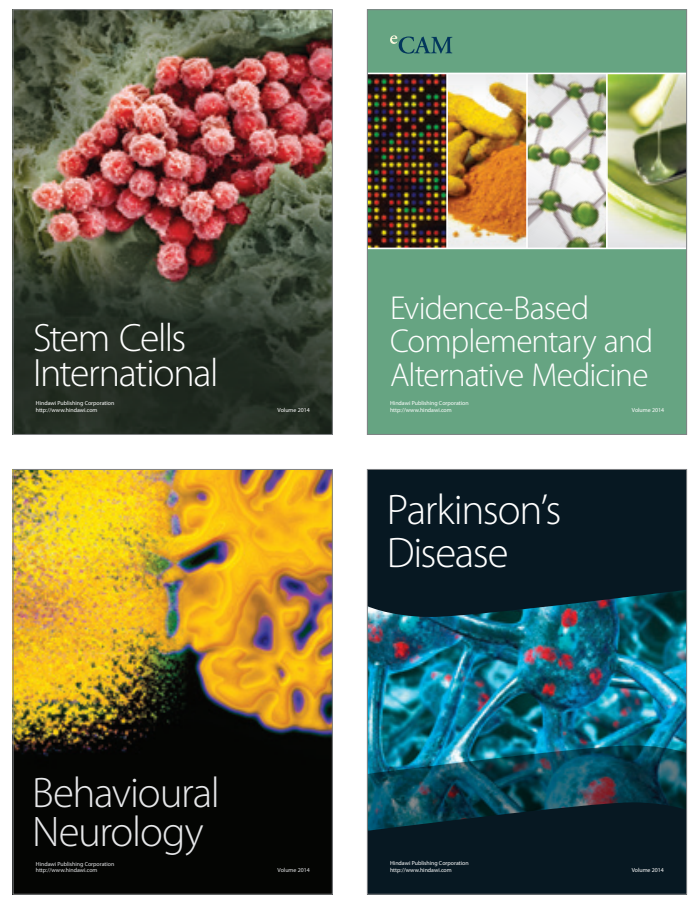
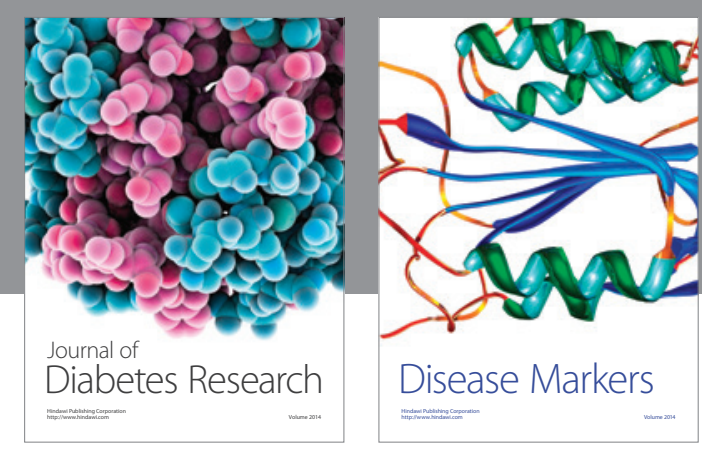

Disease Markers
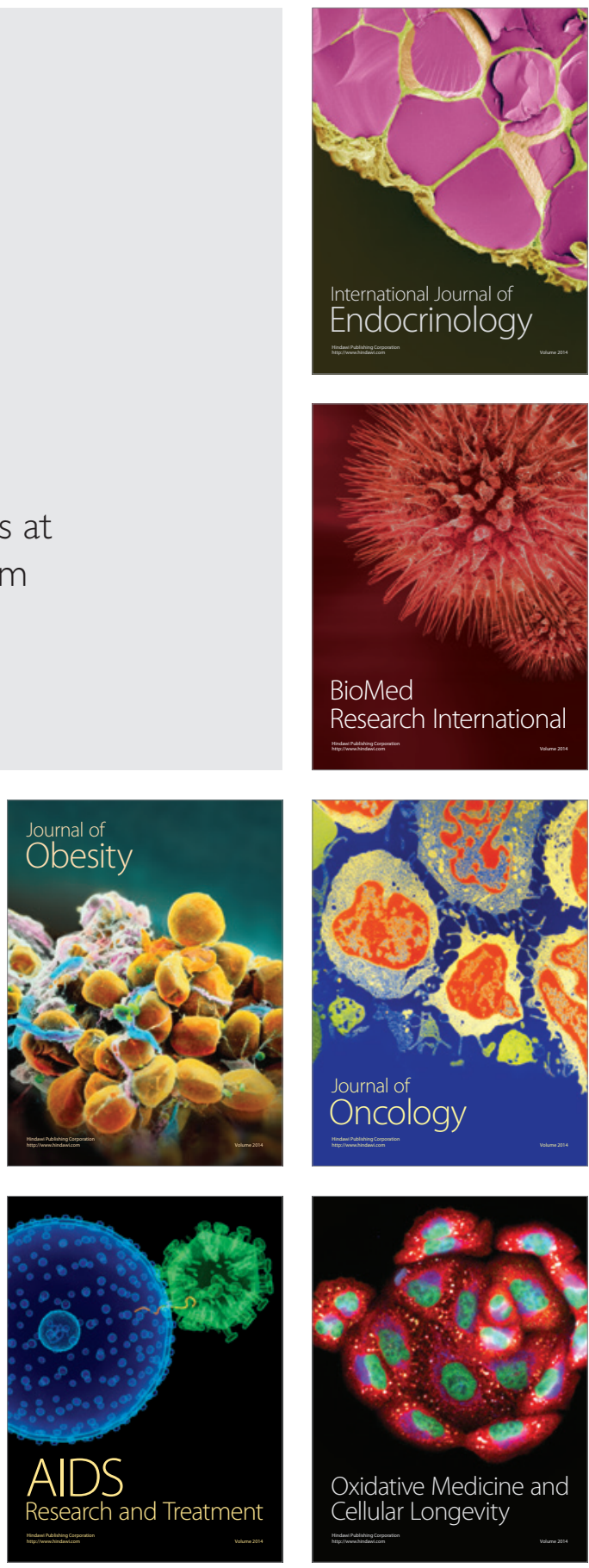